\title{
Gender-specific risk factors for gout: a systematic review of cohort studies
}

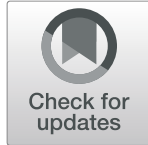

Peter L. Evans' ${ }^{1}$ James A. Prior ${ }^{*}$ (D, John Belcher ${ }^{2}$, Charles A. Hay ${ }^{1}$, Christian D. Mallen ${ }^{1}$ and Edward Roddy ${ }^{1}$

\begin{abstract}
Background: Though gout is more prevalent in men than women, it remains unclear whether gender influences risk factors for incident gout. We aimed to systematically review all cohort studies examining risk factors for the development of gout by gender.

Methods: MEDLINE, EMBASE, CINAHL and the Cochrane Library were searched from inception to March 2019. Risk factors for gout examined were: age, ethnicity, consumption of alcohol, meat, seafood, dairy products, purine-rich vegetables, coffee and fructose, vitamin C intake, the Dietary Approaches to Stop Hypertension (DASH) diet, metabolic syndrome, BMI, waist and chest circumference, waist-to-hip ratio, weight change, diabetes mellitus, dyslipidaemias, renal disease, psoriasis, hypertension, diuretic use and anti-diabetic medication. Cohort studies were included if examining (at least) one of these risk factors for gout in either gender in the general population or primary care. Sample characteristics from included articles and their reported risk estimates were described using narrative synthesis.

Results: Thirty-three articles were included, 20 (60.6\%)directly compared risk factors by gender, 10 (30.3\%) used men-only samples, 3 (9.1\%) used women-only samples. Articles comparing risk across genders found similar increases in most risk factors. However, in men, metabolic syndrome (Hazard Ratio (95\% Cl) 1.37(1.20-1.58)) presented a risk of incident gout compared to none in women (> 50 years $1.15(0.85-1.54)$; $\leq 50$ years 1.29(0.76-2.17)). Compared to men, women showed greater associated risk with higher consumption of fish and shellfish ( $\mathrm{HR}(95 \% \mathrm{Cl})$ Men: 1.02 (0.86-1.22); Women 1.36 (1.12-1.65)).

Conclusions: Risk factors for developing gout did not typically differ between genders and therefore similar preventative advice can be provided. Exceptions were metabolic syndrome in men and excessive seafood consumption in women, but these singular articles need further examination and in general more research into the risk factors for gout which includes women is required.
\end{abstract}

Keywords: Gender, Gout, Risk factors, Systematic review

\section{Introduction}

Gout is the most common inflammatory arthritis, with an increasing prevalence and incidence in recent decades [1]. Despite this, the management of gout remains suboptimal and therefore identifying populations at risk of developing gout, especially those in primary care where the majority of gout is managed, is important.

Gout is more common in men than women, with only $5.1 \%$ of the US gout population being female $[2,3]$. This has typically resulted in the examination of risk factors

\footnotetext{
* Correspondence: j.a.prior@keele.ac.uk

${ }^{1}$ Research Institute for Primary Care and Health Sciences, Keele University,

Staffordshire ST5 5BG, UK

Full list of author information is available at the end of the article
}

for gout focusing on male samples. However, aspects of gout aetiology in men and women, and therefore potential risk factors vary between the genders. Gout typically presents later in women than men, becoming more prevalent after the menopause. Men more frequently report excessive consumption of foods known to increase risk of gout [4]. In contrast, women with gout are more likely than men to have comorbid arterial hypertension or renal insufficiency, or be overweight or obese [4].

A greater understanding of the differences and similarities regarding risk and protective factors for gout between men and women may be an important factor in developing disease prevention strategies. The

(C) The Author(s). 2019 Open Access This article is distributed under the terms of the Creative Commons Attribution 4.0 International License (http://creativecommons.org/licenses/by/4.0/), which permits unrestricted use, distribution, and 
aim of this systematic review was to compare the magnitude of risk conferred by predisposing and protective factors for gout between men and women.

\section{Methods}

Literature search

Four electronic bibliographic databases were systematically searched for articles (MEDLINE, EMBASE, CINAHL and the Cochrane Library) from their inception to March 2019. MeSH terms (or their database-specific equivalent) for exposures and outcomes were searched, and exploded if subcategories were relevant. Free-text phrases were also used across all databases and no search limits were applied to the database results.

\section{Eligibility criteria}

Articles were included if participants were aged $\geq 18$ years, a prospective or retrospective cohort study design was used to examine a risk or protective factor for gout (Table 1) and the outcome was gender-specific gout incidence in a general or primary care population. There were no language restrictions for inclusion; however, if translational facilities for an article were unavailable then it would be excluded.

\section{Screening process}

After duplicates had been removed from the initial search, the titles and abstracts of all of the remaining articles were screened by two reviewers. Three assessors then independently reviewed the full text of the remaining articles to decide on inclusion. Any disagreements regarding article inclusion were subsequently arbitrated over by a fourth reviewer.

\section{Data extraction, quality assessment and analysis}

Methodological quality of all eligible articles was assessed independently by two assessors using the Newcastle-Ottawa Scale (NOS) cohort studies assessment [5]. Disagreement was resolved by consensus discussion between reviewers. Data were extracted from all eligible articles by a single author, with half independently checked by a second assessor. Narrative synthesis was subsequently conducted, describing the characteristics of each study, along with the risk or protective factors examined and the risk of developing gout for each.

\section{Results}

\section{Literature search}

From 54,003 articles identified by the literature search, 35,007 duplicates were removed. The titles and abstracts of the remaining 18,996 articles were screened, after which 116 articles remained. After full-text review of these, 83 articles were excluded leaving 33 articles fulfilling inclusion criteria (Fig. 1).

Twenty-two articles were from the USA, four from Taiwan, two from the UK and one each from Australia, Canada, China, Singapore and New Zealand (Table 2). Thirteen articles (39.4\%) examined the incidence of gout in only one gender $($ Men $=10$, Women $=3$ ), the remaining 20 articles $(60.6 \%)$ compared both genders. Age as a risk factor was examined in four articles [6-9], ethnicity in two [10, 11], dietary risk factors in 16 articles [6-9, 12-23], comorbidities and metabolic disorders in $13[6-9,24-32]$ and medication use in seven $[6,26-28,33-35]$.

\section{Quality assessment}

The results of the NOS quality appraisal of the included articles can be found in Additional file 1: Table S1. Nineteen $(57.6 \%)$ of the 33 articles used a specific group of participants in their studies (the Health Professionals Follow-Up Study and the Nurse's Health Study $[12,15,16,18,19,22,24,30]$, student cohorts [10, 36], Atherosclerosis Risk in Communities Study (ARIC) [27, 28, 33], Third Harvard Growth Study cohort [37], healthy, male runners [13] and hotel managers and their associates [20]), which are unlikely to represent the general population. All but one

Table 1 Exposures included in the systematic review

\begin{tabular}{llll}
\hline Non-modifiable & Diet and Lifestyle & Comorbidities & Medications \\
\hline Age & Meat & Metabolic syndrome & Diuretics* \\
Ethnicity & Seafood & Obesity/BMl*abetic \\
& Purine-rich vegetables & Weight change & Hypertension* \\
& Low-fat dairy products & Diabetes mellitus & Hyperlipidaemia \\
Coffee & Renal disease & Psoriasis \& Psoriatic arthritis \\
& Fructose & \\
& Vitamin C & \\
& Alcohol & \\
\hline
\end{tabular}




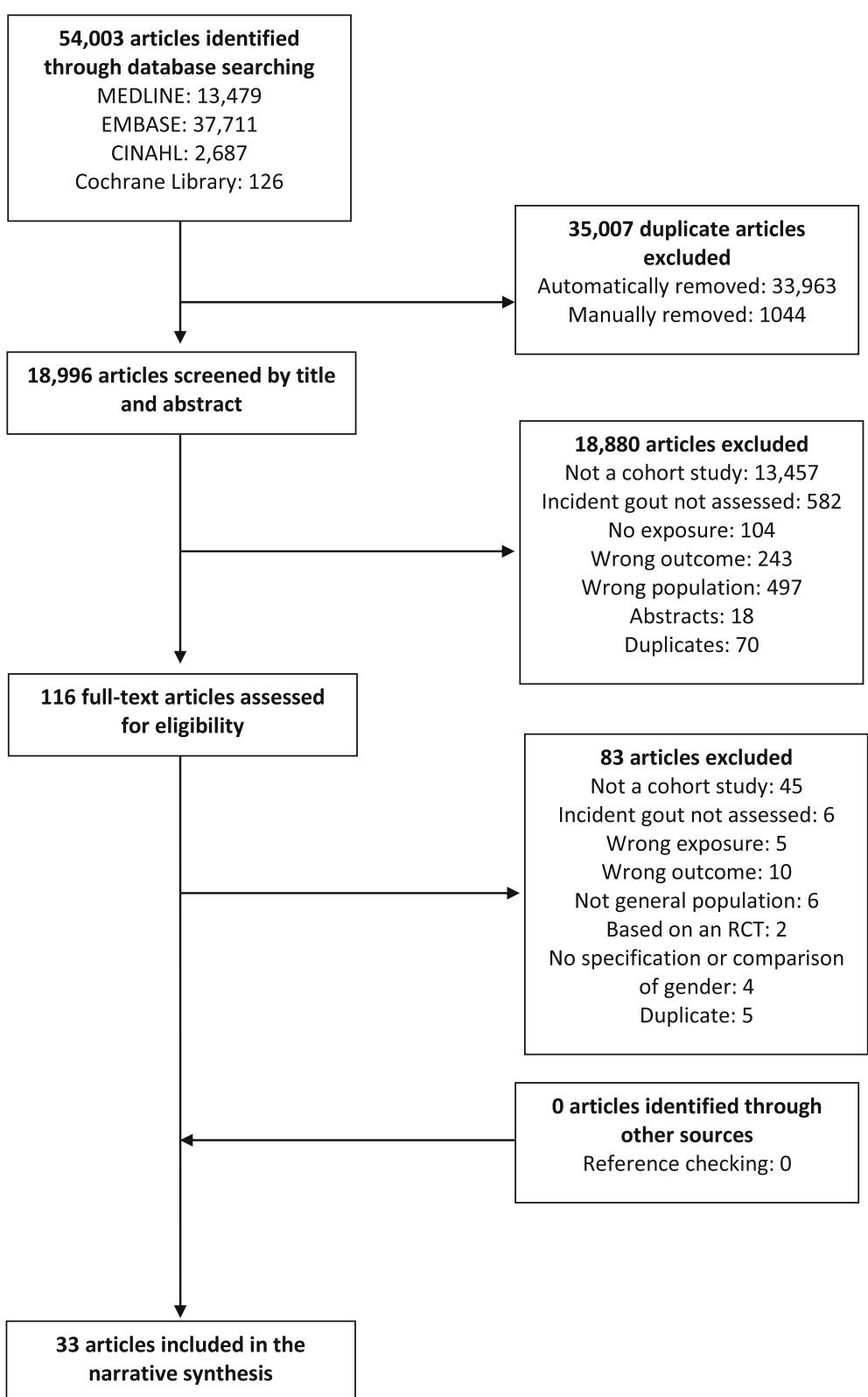

Fig. 1 Flow diagram of the number of articles at each stage of the systematic review

article recruited exposed and non-exposed participants from the same cohort [10]. Hochberg et al. [10] used two cohorts of medical students from different medical schools; the cohort from Johns Hopkins University School of Medicine was entirely Caucasian and the cohort from Meharry Medical College was entirely African-American. The focus of this article was ethnicity and risk of developing gout; participants of different ethnicities came from separate cohorts. Twenty-one (63.6\%) articles scored one of the best response options (secure record or structured interview) for ascertainment of exposure [6-9, 11, 21-23, 26-
38]. Ten ascertained exposure status by self-report $[12-19,24,39]$. Twenty-four (72.7\%) specifically mentioned that participants with prevalent gout were excluded at the beginning of the study $[6-9,11-16$, $18,19,22,24,27,30-35,38]$.

Two (6.1\%) articles provided only unadjusted risk estimates [20, 26]. Prior et al. [9] provided adjusted risks for some, but not all, of the exposures included. All other articles provided results with adjustment for at least two confounding factors. Twenty-one (63.6\%) articles scored highly (using ACR classification criteria, ICD9 codes or practitioner diagnosis) for their method 


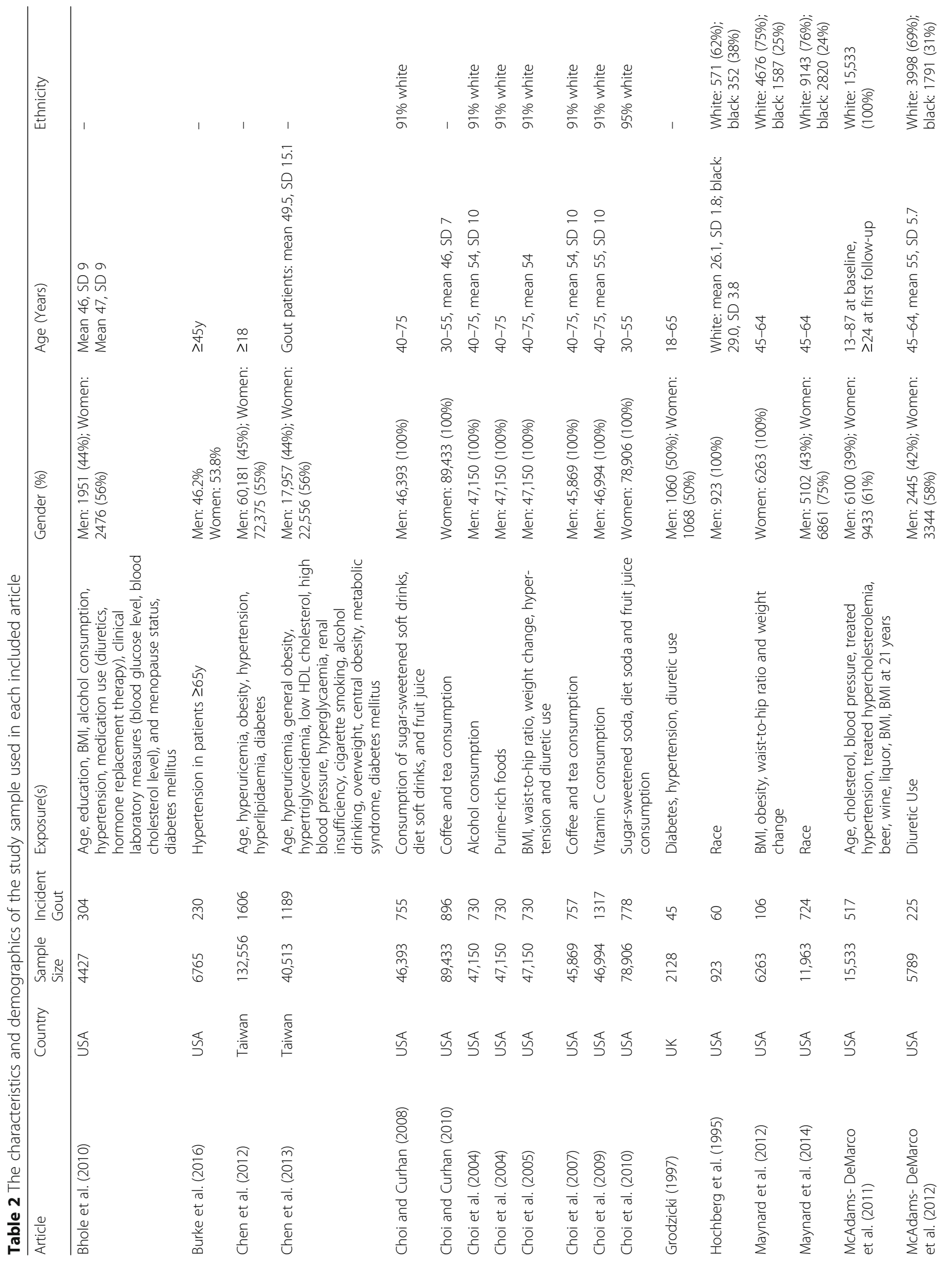




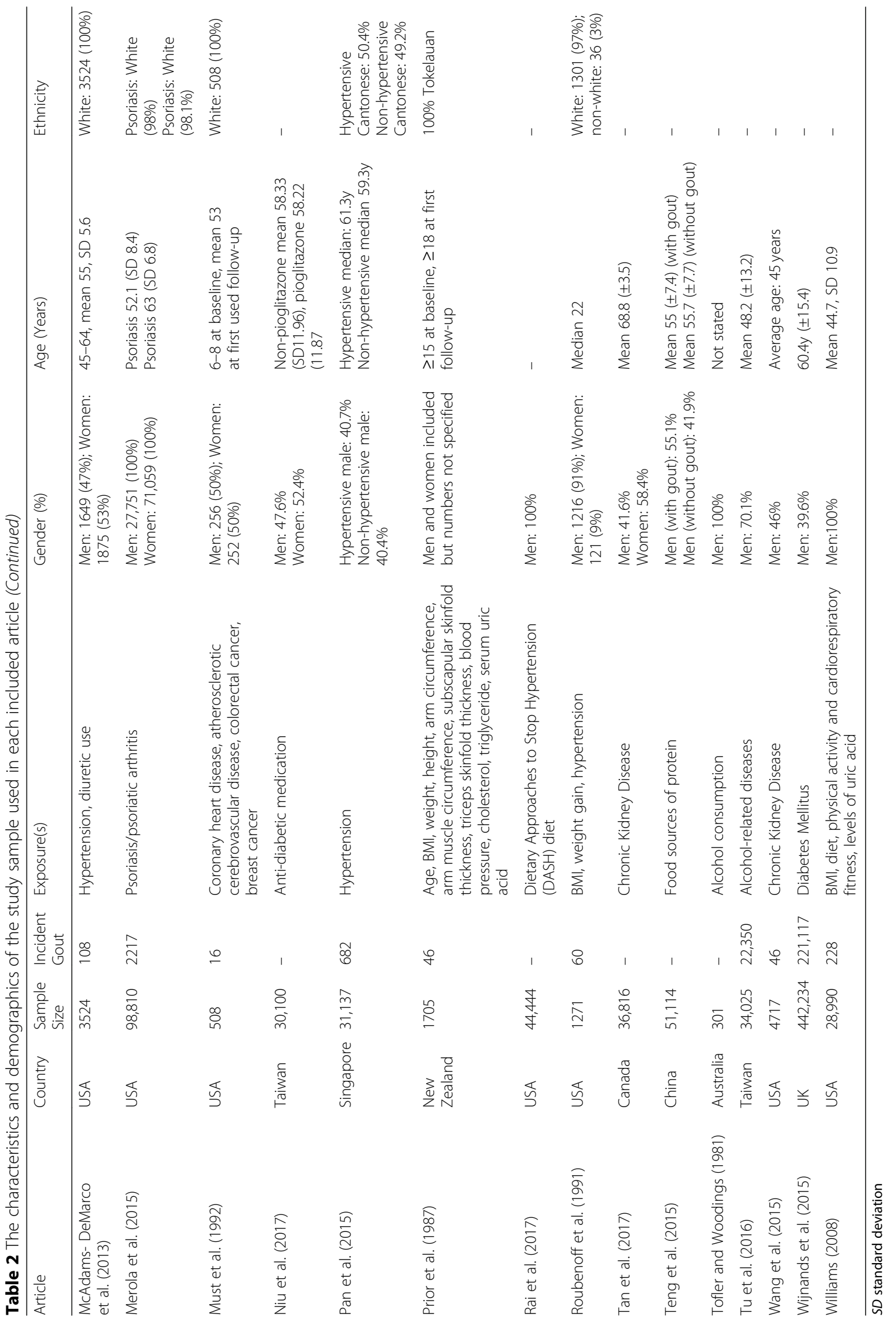


of gout diagnosis; however, there was no uniform method used across all studies [6-10, 12, 14-20, 24, 26, 36]. Out of these articles, eight (38.1\%) diagnosed gout using the American College of Rheumatology preliminary criteria (1977) for gout diagnosis [40]; using this method a minimum of six out of 11 was needed to be considered as having gout [12, 14-19, 24]. One (3.0\%) article diagnosed gout based on a clinical impression by a GP [26]. Hochberg et al. [10] diagnosed gout using self-report in combination with either a history of monosodium urate crystals in synovial fluid, documented tophus or treatment with colchicine, allopurinol or probenecid. Roubenoff et al. [36] diagnosed gout by medical chart review after the participant had selfreported gout. Tofler and Woodings [20] diagnosed gout based on prescription of un-specified anti-gout medications by the participant's own doctor. Ten (30.3\%) articles used record-linkage to diagnose gout $[6-9,23,31$, 32, 35]. Twelve (36.4\%) articles diagnosed gout by participant self-report [11, 13, 21, 22, 27-30, 33, 37-39].

Two $(6.1 \%)$ articles found the female portion of their cohorts too small to reach any conclusion, resulting in a focus on male patients with gout [26, 37]. Both articles provided risk estimates for the whole cohort, but when stratified by gender, could only quantify risk in men because there were insufficient female cases. Twenty-nine (89\%) articles provided a description of those lost to follow-up [6-22, 24, 27-33, 35, 36, 38, 39]. The majority of these were retrospective cohort studies and drew their study sample from a larger cohort and justified why participants from the larger cohort were excluded from their study. One (3.0\%) article lost 45\% before their final follow-up, but did not provide a final loss to follow-up fig. [37]. Three articles did not describe loss to follow-up $[23,26,34]$.

\section{Narrative synthesis \\ Age}

Four articles examined the risk of developing gout associated with age $[6-8,38]$. A study from the US reported a similar increased risk of developing gout associated with a five-year increase in age in men \& women (adjusted relative risk (RR) (95\% confidence interval (95\% CI); Men:1.14(1.03-1.26; Women: 1.24 (1.08-1.43)) [6]. Two studies from Taiwan found similar $2-3 \%$ increases in risk of gout with every one-year increase in age in men (adjusted Hazard Ratio (HR) 1.03 (95\% CI 1.021.03) [7]; 1.02 (1.02-1.03) [8]); however, for women, one reported a $5 \%$ increased risk in women (1.05 (1.04-1.06) and the other compared risk of gout in women stratified by age (> 50 years:1.03 per one-year increase (95\% CI 1.01-1.05); $\leq 50$ years: 1.08 (1.05-1.11)) [7, 8]. A study from New Zealand [9] found a small increased risk of gout with a one-year increase in age in men (adjusted odds ratio (OR) (95\% CI) 1.05(1.02-1.07)), but did not include women (Additional file 1: Table S2).

\section{Ethnicity}

Two articles from the US $[10,11]$ examined the association between ethnicity and the risk of incident gout, with one focussing on men [10] and the other comparing genders [11]. In the study which examined [10] two cohorts of male, former medical students the unadjusted risk of developing gout in African-Americans compared to Caucasians was initially significantly greater (RR (95\%) 1.69(1.02-2.80)), but was attenuated after adjustment for hypertension and BMI (RR (95\% CI) 1.30(0.772.19)). A population-based study found a similarly increased risk of gout in African-Americans compared to Caucasians in men and women (adjusted RR (95\% CI) men: 1.49 (1.11-2.00), women: 1.69 (1.29-2.22)) [11] (Additional file 1: Table S3).

\section{Dietary factors}

Fifteen articles examined the risk of dietary factors on gout, with the majority of these examining the risk associated with meat, seafood, dairy consumption and a DASH (Dietary Approaches to Stop Hypertension) diet in male-only studies and therefore comparative results are presently unavailable. The results of the singlegender papers which investigated the above risks are available to view in Additional file 1: Table S4. In a Singapore population, Teng et al. examined the role of different sources and quantities of dietary protein consumed on the risk of incident gout in men and women [21]. They examined risk related to; total protein intake, soy protein, fish and shellfish, red meat, poultry, eggs, dairy, soy foods, non-soy legumes, nuts and seeds and all grain. Though risk or protection from gout was comparable across the majority of these protein sources for men and women, they found that in women, there was increased risk of gout in those with the highest levels of consumption of fish and shellfish (HR 1.36 (1.12-1.65)) compared to the lowest levels of consumption and a protective effect in those with the highest consumption of non-soy legumes (HR 0.77 (0.64-0.94)) compared to the lowest consumption. There was no significant difference for men for either of these factors.

The HPFS study in men and Nurses' Health Study in women examined coffee consumption as a potential risk factor for gout $[14,15]$. Risk of incident gout was halved in women consuming $\geq 4$ cups of coffee per day (adjusted RR (95\% CI) $0.43(0.30-0.61)$ ) and lower in men consuming $4-5$ cups $(0.60(0.41-0.87))$ or $\geq 6$ cups (0.41 (0.19-0.88)) per day compared to non-drinkers of coffee. In the Nurses' Health Study, risk of incident gout was lower in women consuming at least 1 cup of decaffeinated coffee per day compared with those drinking no 
cups (adjusted RR 0.77(0.63, 0.95)). In the HPFS, gout incidence was lower in men who drank decaffeinated coffee, but only less than or equal to 4 a day ( $\geq 4$ cups per day; 0.73 (0.46-1.17)). Neither study found an association between tea consumption and incident gout (Additional file 1: Table S5).

Two articles examined fructose and sugars and their association with incident gout in the HPFS and Nurses' Health Study $[16,17]$. There was a relationship between the highest consumption of sugar-sweetened cola and other sweetened soft drinks and an increased risk of incident gout in men, but not for diet soft drinks. The same pattern was seen for women in the Nurses' Health Study [17]. Both articles examined fruit juices, reporting that high levels of consumption were associated with incident gout in men and women. Furthermore, they reported that increasing consumption of free (as a monosaccharide) and total fructose (calculated as free fructose plus half of sucrose) are risk factors for gout in both men and women (Additional file 1: Table S6).

One study examined the potential protective effects of total and supplemental vitamin $\mathrm{C}$ intake against the risk of developing gout in men [18], but none examined the risk in women. (Additional file 1: Table S7).

Seven articles examined the association between alcohol consumption and incident gout $[6,8,9,13,19,20,23]$, with three directly comparing men and women $[6,8]$. Chen et al. [8] examined the overall risk in men and women (women $<50$ years of age and women $\geq 50$ years of age) who drank alcohol (including abstainers) and developed gout compared to those who never drink and found no statistically significant risk. Bhole et al. [6] reported that alcohol presented a similar increased risk of developing gout in men and women, (risk in heavy drinkers ( $\geq 7$ oz. per week) (Men: RR (95\% CI) 2.21(1.563.14); Women 3.10 (1.69-5.69)). Tu et al. [23] examined the risk of alcohol-related disease in men and women and the incidence of gout. Their findings supported the importance of alcohol intake and the development of gout, but this was irrespective of gender (men HR 1.81 (1.64-1.99); women HR 2.48 (1.97-3.13)). The remaining four articles all reported a greater risk of men developing gout in alcohol drinkers compared to those who do not drink alcohol $[9,13,19,20]$. There were no articles examining the risk of gout in women-only samples. (Additional file 1: Table S8).

\section{Comorbidities}

\section{Metabolic syndrome}

Only one study [8] examined the role of metabolic syndrome (defined as three or more of the following; central obesity, hypertriglyceridaemia, low high-density lipoproteins, hypertension and hyperglycaemia) as a risk factor for gout in men and women. Though there was an initial association between metabolic syndrome and incident gout for both genders, this was only retained in men after adjustment, (Men: HR (95\% CI) 1.37 (1.20-1.58); Women > 50 years 1.15 (0.85-1.54); Women $\leq 50$ years 1.29 (0.76-2.17)) (Additional file 1: Table S9).

\section{Body mass index}

Ten articles considered the role of BMI on incident gout within the context of a specific gender, with three comparing men and women [6-8], six including only men $[9,10,13,24,36,37]$ and one including only women [38]. Chen et al. [7] reported a significant risk of developing gout for those with a BMI of $\geq 27 \mathrm{~kg} / \mathrm{m}^{2}$ in both genders, although it was greater in women (adjusted RR (95\% CI) 1.30(1.15-1.47) in men, 2.15 (1.672.76) in women). When stratifying women by menopausal status the risk remained significant for both, but was more prominent in pre-menopausal women (Premenopause: RR (95\% CI) 2.50(1.38-4.52); Postmenopause 1.90 (1.44-2.51)). In their 2013 article, Chen et al. [8] found the risk of incident gout conveyed by a BMI of $\geq 27 \mathrm{~kg} / \mathrm{m}^{2}$ to be greater in women aged $>50$ years $(1.97(1.48-2.62))$ than men $(1.30(1.11-1.53))$, while the risk for women $\leq 50$ years was not statistically significant (1.63 (0.93-2.86)). Bhole et al. [6] reported that obese men and women (those with BMI of $\geq 30 \mathrm{~kg} /$ $\mathrm{m}^{2}$ ) were over two half times more likely to develop gout (Men: RR (95\% CI) 2.90(1.89-4.44); Women 2.74 (1.654.58)); however, only men were at risk (1.76 (1.22-2.54)) when categorised as overweight $\left(25-29.9 \mathrm{~kg} / \mathrm{m}^{2}\right)$. Must et al. [37] found no association between obesity, defined as a BMI between 22 and 25 in boys and 22-24 in girls, during adolescence (13 to 18 years of age) and the development of gout later in life. Choi et al. [24] and Williams et al. [13] reported risk of incident gout in men increased in line with increasing BMI; however, Hochberg et al. and Roubenoff et al. both found no association [10, 36]. Maynard et al. [38] studied only females, and found that obese women had double the risk of developing gout (RR 2.37 (1.53-3.68)) than non-obese women (Additional file 1: Table S10).

\section{Waist and chest circumference}

Two articles examined risk associated with waist and chest circumference. Chen et al. [8] defined central obesity as waist circumference greater than $90 \mathrm{~cm}$ in men and $80 \mathrm{~cm}$ in women, reporting adjusted hazard ratios $(95 \% \mathrm{CI})$ of $1.30(1.13-1.50)$ in men and 1.39 (1.01-1.92) in women aged over fifty years compared to those without central obesity. In women fifty years of age or younger the risk was not significant (HR (95\% CI) $1.45(0.91-2.30))$. In an all-male cohort, Williams [13] found no association between a per centimetre increase 
in waist or chest circumference and risk of gout after adjustment (Additional file 1: Table S11).

\section{Waist-to-hip ratio}

Two articles examined risk associated with waist-to-hip ratio (WHR). Choi et al. [24] and Maynard et al. [38] conducted similar studies into WHR and the risk of developing gout, but with all-male and all-female cohorts respectively. Choi et al. [24] reported an association between WHR and the development of gout in men in their highest two categories (WHR 0.95-0.97, adjusted RR (95\% CI) 1.35(1.01-1.79), WHR 0.98-1.39, 1.82(1.39-2.39)). Maynard et al. [38] also reported increased risk in women with a WHR $>0.968$ compared to those with a WHR $<0.900$ (adjusted RR $(95 \%$ CI) 2.78(1.65-4.70)) (Additional file 1: Table S12).

\section{Weight change}

Three articles, $[24,36,38]$ reported risks of gout associated with weight change, with two [24, 36] using allmale cohorts, and one [38] using an all-female cohort.

In men, an increase in BMI between entry into the study's cohort and age 35 years of $>1.88$ doubled the risk of gout (RR 2.07 (95\% CI not reported)) and an increase in weight of $\geq 2.7 \mathrm{~kg}$ had a similar risk (RR 1.87), adjusted for age and hypertension [36]. Choi et al. [24] studied weight change from age 21 years and from cohort entry at baseline for men. Weight loss from either reduced risk of gout, though this was only statistically significant for the loss of >10lbs from cohort entry (adjusted RR (95\% CI) $0.61(0.40-0.92))$. Increases in weight from age 21 years showed an increased risk of gout; in the adjusted model this was only significant with weight gain of 20-29lbs and $>30 \mathrm{lbs}$ (RR (95\% CI) 20-29lbs: 1.39 (1.02-1.90), >30lbs: 1.99 (1.49-2.66)). Though the risk associated with weight change from baseline varied across the categories, the greatest weight loss $(-10 \mathrm{lbs}$ or more) was protective $(0.61(0.40-0.92)$ and greatest weight gain $(+30 \mathrm{lbs}$ or more) increased the risk of gout (1.72(1.02-2.91)).

In women, Maynard et al. [38] also found the greatest weight gain change ( $\geq 16.3 \mathrm{~kg}$ ) from 21 to 25 years of age doubled the adjusted risk for incident gout (2.05 (1.063.96) (Additional file 1: Table S13).

\section{Diabetes mellitus}

Four articles examined the risk of developing gout associated with diabetes mellitus. These studies were undertaken in population-based samples, stratified by men and women [6-8,34]. Bhole et al. [6] reported no association between a $10 \mathrm{mg} / \mathrm{dl}$ increase in blood glucose levels and risk of incident gout in either gender. Chen et al. [7] reported that diabetes mellitus was not associated with an increased risk of gout in men or women, or either of their stratifications of women by menopausal status. Chen et al. [8] reported no association of gout with hyperglycaemia. (Additional file 1: Table S14). Finally, the study by Wijnands et al., the most recent and largest of the four included articles, found that individuals with type 2 diabetes were initially at increased risk of gout, but after adjustment the risk disappeared in women (HR 1.01; 95\% CI 0.92-1.11) and reversed in men (HR 0.61;95\% CI 0.58-0.66) [34] (Additional file 1: Table S20).

\section{Dyslipidaemias}

Four articles examined risk associated with dyslipidaemias. Prior et al. [9] reported that elevations of both serum cholesterol and triglycerides of $1 \mathrm{mmol} / \mathrm{l}$ significantly increased the risk of gout in men. Bhole et al. [6], however, found no association between gout and an increase in blood cholesterol of $10 \mathrm{mg} / \mathrm{d}$ in either gender. Chen et al. [7] explored the role of hyperlipidaemia, defined as blood cholesterol levels $\geq 240 \mathrm{mg} / \mathrm{dl}$ or triglyceride levels $\geq 200 \mathrm{mg} / \mathrm{dl}$, in the predisposition to gout. They reported that it was only significant in women (HR (95\% CI) 1.70(1.32-2.19)), and after stratification by menopausal status it remained significant in only postmenopausal women (HR (95\% CI) 1.59(1.20-2.09)). Hypertriglyceridaemia, defined as blood triglycerides levels greater than $150 \mathrm{mg} / \mathrm{dl}$, were significantly associated with gout in men (HR (95\% CI) 1.39(1.21-1.60)) and women over fifty years of age (HR $(95 \%$ CI) $1.37(1.02-1.83))$ in the article by Chen et al. [8] (Additional file 1: Table S15).

\section{Renal disease}

In a men only dataset, Choi et al. [24] reported an increased risk of gout associated with chronic renal failure (unadjusted RR (95\% CI) 3.61(1.60-8.14)); this risk increased when looking at a subset of those with chronic renal failure who had had no exposure to diuretics (RR (95\% CI) 4.60(1.88-11.25)). When Tan et al. [32] examined specific levels of kidney function (eGFR) and 3 -year cumulative incidence of gout in both men and women, they found that risk in men was significantly higher across all levels of kidney function (eGFR> $90 \mathrm{ml} /$ min per $\left.1.73 \mathrm{~m}^{2}, 60-89,45-59,30-44,15-29\right)$ than women, except for the chronic dialysis group. However, though Chen et al. [8] and Wang et al. [31] both found an association between renal insufficiency and chronic kidney disease respectively on the risk of gout, there was little difference in risk between the genders. (Additional file 1: Table S16).

\section{Hypertension}

Ten articles explored hypertension as a risk factor for gout $[6-10,24,26,28,29,36]$, of which five articles 
compared the associations between hypertension and incidence gout in men and women. Three $[6,25,29]$ found increased incidence in both genders, one [8] found the incidence of gout in hypertensive patients to only be raised in men and another found the risk of gout was only increased in female hypertensive patients [28]. Five further articles examined risk in male only samples. All found increased incidence of gout, though only two adjusted for covariates $[9,10,24,26,36]$. There were no articles examining the risk of hypertension in womenonly samples (Additional file 1: Table S17).

\section{Psoriasis/psoriatic arthritis}

One article examined the association of psoriasis and psoriatic arthritis with incident gout [30]. This article examined these associations on both men and women, but using two separate datasets for either gender, the HFPS and NHS for men and women respectively. Though the risk of gout was increased in men and women with psoriasis and psoriatic arthritis, risk was greater in men with confirmed psoriasis then women (HR (95\% CI) Men: 2.72 (1.75, 4.25); Women $1.40(0.90,2.19)$ ) (Additional file 1: Table S19).

\section{Diuretics}

Three articles examined diuretic use against no diuretic use. One compared genders [6], and two used male-only samples $[24,26]$. All reported that there was a statistically significant association between diuretic use and incident gout, even after adjustment. Only Bhole et al. [6] examined the differences in risk between genders, reporting a similar risk in both (Men: RR $(95 \% \mathrm{CI})$ 3.41(2.38-4.89); Women: (2.39 (1.53-3.74)). Choi et al. and Grodzicki et al. used male-only samples [24, 26], the former reporting an increased risk of 1.77 (1.42-2.20) after adjustment, the latter reporting a crude risk estimate of 6.25 (2.4-16.70) (Additional file 1: Table S18).

\section{Pioglitazone}

A study by Niu et al. (2017) [35] examined the association of pioglitazone on incident gout in men and women with Diabetes Mellitus, reporting that the incidence of gout was significantly lower in pioglitazone users than in non-pioglitazone users [adjusted hazard ratio (aHR) $0.81(95 \% \mathrm{CI} 0.78,0.85)]$. The HR for the incidence of gout was lower in both male [aHR 0.80 $(95 \%$ CI 0.75, 0.85)] and female [aHR 0.83 (95\% CI 0.78, 0.88)] pioglitazone users than in non-pioglitazone users (Additional file 1: Table S20).

\section{Discussion}

This systematic review identified all cohort studies which examined well-established risk and protective factors for gout, specifically examining differences in risk between the genders. We found that the risk of developing gout was influenced by many demographic, dietary, comorbid and pharmacological risk factors, and for many of these risk factors, risk was similar for men and women. However, there were exceptions such as metabolic syndrome, which conferred a greater risk in men and increased intake of fish and shellfish, which has a greater association with risk of gout in women.

There are results which suggest different risks between genders, but from which it is difficult to come to conclusions. For example, for diuretic use, the magnitude of risk estimates suggested a greater risk in men, but there was significant overlap of $95 \% \mathrm{CI}$ between the genders precluding firm conclusions [6]. Aspects of diet (consumption of meat, fish, purinerich vegetables and vitamin $C$ etc) were the most frequently examined of the risk factors, but due to the many potential components of diet, the variety of ways in which consumptions was quantified in each article and the predominate use of male-only datasets, our ability to compare gender stratified datasets was extremely limited. There was only one study to consider dietary risk of gout in men and women, Teng et al. examined a multitude of sources of protein in a large sample from Singapore, finding fish and shellfish to increase the risk of gout in women, but not men. As this was only one study we are cautious with our inferences, but further research into this area would not only provide a useful illumination for the female population regarding gout; comparative studies investigating male and female association between diet and risk of gout could provide useful insights into the dietary component of gout's aetiology.

Though also only investigated in a single article, the difference in risk associated with metabolic syndrome between the genders seems plausible, due to the large sample size and relatively even proportion of men and women. Metabolic syndrome was reported to be associated with gout in men, but not women. This could be due to the fact that, despite a large sample size the number of cases of gout in women remained low (202 in those older than 50, 88 in those equal to or younger than 50). More research in this area would be of benefit.

The articles that examined age, renal insufficiency, fructose consumption and hypertension reported increases in risk that were statistically significant and of a similar magnitude in both, men and women. Chen et al. $[7,8]$ highlight the importance of age when considering gender, with older women ( $>50$ years) being at increased risk. Though this risk factor is nonmodifiable, it remains important to highlight that older patients may need greater monitoring, especially in women due to the apparent risk increases post- 
menopause. With regard to comorbidities, it is clear that hypertension is associated with increased risk of developing gout, but the strength of this association is not agreed upon, with the reported risk ranging by an order of magnitude from 33 to $400 \%$ [25, 26]. The presence of psoriasis also increases the risk of gout and may have a greater role in men than women. However, the article by Merola et al. demonstrating this used data from two separate male and female datasets and therefore a direct comparisons is limited.

Ethnicity and diabetes mellitus showed no definitive association with altered risk of gout between either genders. Only one study considered the role of gender in the risk of developing gout in different ethnic groups. Though relative risk was $20 \%$ greater in men than women, again, overlapping confidence intervals suggested little actual difference between the genders. Few studies reported protective factors for gout, especially comparing this across genders. A single study by Teng et al., reported that high consumption of non-soy legumes was protective in women, compared to those with the lowest consumption, although this protection was not demonstrated in men.

\section{Strengths and limitations}

A strength of this systematic review was the lack of restrictions placed on the search. All widely established risk and protective factors were included, allowing a comprehensive comparison of factors associated with gout. Furthermore, there were no restrictions on year of publication as databases were searched from their inception and publications in all languages were included and translated and only cohort study designs were included. Our research does have limitations due to several articles using specific samples (e.g. health professionals), thereby possible reducing generalisability. The included studies used a range of different data collection methods, including self-report, measurement and record-linkage, potentially introducing heterogeneity. Related to this point, we were unable to conduct a meta-analysis due to the aforementioned heterogeneity.

\section{Conclusion}

This systematic review identified several risk factors for the development of gout, with the degree of risk between the genders predominantly being consistent and therefore meaning similar preventative advice can be provided. However, metabolic disorder and an excess consumption of fish and shellfish may presents a greater risk of developing gout in men and women respectively. Far more research into the risk factors for gout which includes women is required to be confident that no further differences exist.

\section{Additional file}

\begin{abstract}
Additional file 1: Table S1. The results of the quality appraisal of the included articles using the Newcastle-Ottawa Scale (NOS). Table S2. Risk estimates for developing gout based on age. Table S3. Risk estimates for developing gout based on ethnicity. Table S4. Risk estimates for developing gout based on diet. Table S5. Risk estimates for developing gout based on caffeine consumption. Table S6. Risk estimates for developing gout based on fructose consumption. Table S7. Risk estimates for developing gout based on vitamin C consumption. Table S8. Risk estimates for developing gout based on alcohol consumption. Table S9. Risk estimates for developing gout based on metabolic syndrome. Table S10. Risk estimates for developing gout based on body mass index (BMI). Table S11. Risk estimates for developing gout based on waist and chest circumference. Table S12. Risk estimates for developing gout based on waist-to-hip ratio. Table S13. Risk estimates for developing gout based on weight change. Table S14. Risk estimates for developing gout based on diabetes mellitus. Table S15. Risk estimates for developing gout based on dyslipidaemias. Table S16. Risk estimates for developing gout based on renal disease. Table S17. Risk estimates for developing gout based on hypertension. Table S18. Risk estimates for developing gout based on diuretic use. Table S19. Risk estimates for developing gout based on psoriasis and psoriatic arthritis (PsA). Table S20. Risk estimates for developing gout based on anti-diabetic medication. (DOCX $149 \mathrm{~kb}$ )
\end{abstract}

\section{Abbreviations \\ ACR: American College of Rheumatology; ARIC: Atherosclerosis Risk in Communities Study; BMl: Body mass index; Cl: Confidence interval; HPFS: Health professionals follow-up study; HR: Hazard ratio; ICD9: International coding of diseases, 9th revision; MeSH: Medical subject heading; NOS: Newcastle-Ottowa Scale; OR: Odds ratio; RR: Relative risk; WHR: Waist-hip-ratio}

\section{Acknowledgements}

We would like to thank the Research Institute for Primary Care and Health Sciences, Keele University for its support.

\section{Author contributions}

Contribution statement: Guarantor of overall study integrity: JAP, CDM \& ER. Study concept \& design: JAP, JB, CDM \& ER. Data collection and interpretation: PE, JAP, JB, CDM, CH \& ER. Analysis: PE, JAP, JB \& CH. Manuscript preparation: PE, JAP, JB, CDM, CH \& ER. Final approval of manuscript: $P E, J A P, J B, C D M, C H \& E R$

\section{Funding}

CDM is funded by the NIHR Collaboration for Leadership in Applied Health Research and Care (CLAHRC) West Midlands West Midlands, the NIHR SPCR, and an NIHR Research Professorship in General Practice (NIHR-RP-2014-04-026). The study sponsors had no role in study design; in the collection, analysis, and interpretation of data; in the writing of the report; and in the decision to submit the paper for publication. The views and opinions expressed therein are those of the authors and do not necessarily reflect those of the NIHR (UK). This paper presents independent research which is part-funded by the CLAHRC West Midlands. The views expressed are those of the author(s) and not necessarily those of the NHS, the NIHR or the Department of Health.

\section{Availability of data and materials \\ Not applicable.}

Ethics approval and consent to participate

Not applicable.

Consent for publication

Not applicable.

Competing interests

The authors declare they have no competing interest. 


\section{Author details}

'Research Institute for Primary Care and Health Sciences, Keele University, Staffordshire ST5 5BG, UK. ${ }^{2}$ Research and Innovation, Wythenshawe Hospital, Manchester University Foundation Hospital Trust, Wythenshawe, UK.

\section{Received: 10 April 2018 Accepted: 7 June 2019}

\section{Published online: 24 June 2019}

\section{References}

1. Kuo CF, Grainge MJ, Mallen C, Zhang W, Doherty M. Rising burden of gout in the UK but continuing suboptimal management: a nationwide population study. Ann Rheum Dis 2015;74(4):661-667. doi: https://doi.org/ 10.1136/annrheumdis-2013-204463. PubMed PMID: 24431399; PubMed Central PMCID: PMCPMC4392307.

2. Lally EV, Ho G, Jr., Kaplan SR. The clinical spectrum of gouty arthritis in women. Arch Intern Med 1986;146(11):2221-2225. PubMed PMID: 3778053.

3. Puig JG, Michan AD, Jimenez ML, Perez de Ayala C, Mateos FA, Capitan CF, et al. Female gout. Clinical spectrum and uric acid metabolism. Arch Intern Med 1991;151(4):726-732. PubMed PMID: 2012455.

4. Harrold LR, Etzel CJ, Gibofsky A, Kremer JM, Pillinger MH, Saag KG, et al. Sex differences in gout characteristics: tailoring care for women and men. BMC Musculoskelet Disord. 2017;18(1):108. https://doi.org/10.1186/s12891-0171465-9.

5. GA Wells BS, D O'Connell, J Peterson, V Welch, M Losos, P Tugwell. The Newcastle-Ottawa scale (NOS) for assessing the quality of nonrandomised studies in meta-analyses: Ottawa Hospital Research Institute; 2014 [cited 2017 24/04/2017]. Available from: http://www.ohri.ca/programs/clinical_ epidemiology/oxford.asp.

6. Bhole V, de Vera M, Rahman MM, Krishnan E, Choi H. Epidemiology of gout in women: fifty-two-year followup of a prospective cohort. Arthritis Rheum 2010;62(4):1069-1076. doi: https://doi.org/10.1002/art.27338. PubMed PMID: 20131266.

7. Chen JH, Yeh WT, Chuang SY, Wu YY, Pan WH. Gender-specific risk factors for incident gout: a prospective cohort study. Clin Rheumatol 2012;31(2): 239-245. https://doi.org/10.1007/s10067-011-1802-6. PubMed PMID: 21761146.

8. Chen JH, Pan WH, Hsu CC, Yeh WT, Chuang SY, Chen PY, et al. Impact of obesity and hypertriglyceridemia on gout development with or without hyperuricemia: a prospective study. Arthritis Care Res (Hoboken) 2013;65(1): 133-140. https://doi.org/10.1002/acr.21824. PubMed PMID: 22933424.

9. Prior IA, Welby TJ, Ostbye T, Salmond CE, Stokes YM. Migration and gout: the Tokelau Island migrant study. Br Med J (Clin Res Ed) 1987;295(6596): 457-461. PubMed PMID: 3117170; PubMed Central PMCID: PMCPMC1247326.

10. Hochberg MC, Thomas J, Johniene Thomas D, Mead L, Levine DM, Klag MJ. Racial differences in the incidence of gout. Arthritis \& Rheumatism. 1995: 38(5):628-32. https://doi.org/10.1002/art.1780380508.

11. Maynard JW, McAdams-DeMarco MA, Law A, Kao L, Gelber AC, Coresh J, et al. Racial differences in gout incidence in a population-based cohort: atherosclerosis risk in communities study. Am J Epidemiol 2014;179(5):576583. https://doi.org/10.1093/aje/kwt299. PubMed PMID: PMC3927975.

12. Choi HK, Atkinson K, Karlson EW, Willett W, Curhan G. Purine-rich foods, dairy and protein intake, and the risk of gout in men. N Engl J Med 2004; 350(11):1093-1103. doi: https://doi.org/10.1056/NEJMoa035700. PubMed PMID: 15014182

13. Williams PT. Effects of diet, physical activity and performance, and body weight on incident gout in ostensibly healthy, vigorously active men. Am J Clin Nutr 2008;87(5):1480-1487. PubMed PMID: 18469274; PubMed Central PMCID: PMCPMC4090353.

14. Choi HK, Curhan G. Coffee consumption and risk of incident gout in women: the Nurses' health study. Am J Clin Nutr 2010;92(4):922-927. https://doi.org/10.3945/ajcn.2010.29565. PubMed PMID: 20739424; PubMed Central PMCID: PMCPMC2937590.

15. Choi HK, Willett W, Curhan G. Coffee consumption and risk of incident gout in men: a prospective study. Arthritis Rheum 2007;56(6):2049-2055. https:// doi.org/10.1002/art.22712. PubMed PMID: 17530645.

16. Choi HK, Curhan G. Soft drinks, fructose consumption, and the risk of gout in men: prospective cohort study. BMJ. 2008;336(7639):309-312. doi: https:// doi.org/10.1136/bmj.39449.819271.BE. PubMed PMID: 18244959; PubMed Central PMCID: PMCPMC2234536.
17. Choi HK, Willett W, Curhan G. Fructose-rich beverages and risk of gout in women. JAMA. 2010;304(20):2270-2278. https://doi.org/10.1001/jama.2010. 1638. PubMed PMID: 21068145; PubMed Central PMCID: PMCPMC3058904.

18. Choi HK, Gao X, Curhan G. Vitamin C intake and the risk of gout in men: a prospective study. Arch Intern Med 2009;169(5):502-507. https://doi.org/10. 1001/archinternmed.2008.606. PubMed PMID: 19273781; PubMed Central PMCID: PMCPMC2767211.

19. Choi HK, Atkinson K, Karlson EW, Willett W, Curhan G. Alcohol intake and risk of incident gout in men: a prospective study. Lancet. 2004;363(9417): 1277-1281. https://doi.org/10.1016/50140-6736(04)16000-5. PubMed PMID: 15094272.

20. Tofler OB, Woodings TL. A 13-year follow-up of social drinkers. Med J Aust 1981;2(9):479-481. PubMed PMID: 7321997.

21. Teng GG, Pan A, Yuan JM, Koh WP. Food Sources of Protein and Risk of Incident Gout in the Singapore Chinese Health Study. Arthritis Rheumatol. 2015;67(7):1933-1942. Epub 2015/03/27. https://doi.org/10.1002/art.39115. PubMed PMID: 25808549; PubMed Central PMCID: PMCPMC4939435.

22. Rai SK, Fung TT, Lu N, Keller SF, Curhan GC, Choi HK. The dietary approaches to stop hypertension (DASH) diet, Western diet, and risk of gout in men: prospective cohort study. bmj. 2017;357:j1794.

23. Tu H-P, Tung Y-C, Tsai W-C, Lin G-T, Ko Y-C, Lee S-S. Alcohol-related diseases and alcohol dependence syndrome is associated with increased gout risk: a nationwide population-based cohort study. Joint Bone Spine. 2017;84(2): 189-96. https://doi.org/10.1016/j.jbspin.2016.02.024.

24. Choi HK, Atkinson K, Karlson EW, Curhan G. Obesity, weight change, hypertension, diuretic use, and risk of gout in men: the health professionals follow-up study. Arch Intern Med 2005;165(7):742-748. https://doi.org/10. 1001/archinte.165.7.742. PubMed PMID: 15824292.

25. Chen JH, Yeh WT, Pan WH. Effects of urate-lowering therapy on cardiovascular mortality: a propensity score matched case-control study. 15th Congress of Asia Pacific League of Associations for Rheumatology, Advancing Rheumatology in the Asian Pacific Region: New Challenges, New Horizons Amman Jordan. 2012;15:103.

26. Grodzicki T, Palmer A, Bulpitt CJ. Incidence of diabetes and gout in hypertensive patients during 8 years of follow-up. The general practice hypertension study group. J Hum Hypertens 1997;11(9):583-585. PubMed PMID: 9364276.

27. McAdams-DeMarco MA, Maynard JW, Baer AN, Kao LW, Kottgen A, Coresh J. A urate gene-by-diuretic interaction and gout risk in participants with hypertension: results from the ARIC study. Ann Rheum Dis 2013;72(5):701-706. https:/doi.org/10.1136/annrheumdis-2011-201186. PubMed PMID: 22753387; PubMed Central PMCID: PMCPMC4565188.

28. Burke BT, Köttgen A, Law A, Grams M, Baer AN, Coresh J, et al. Gout in older adults: the atherosclerosis risk in communities study. J Gerontol A Biol Sci Med Sci. 2015;71(4):536-42.

29. Pan A, Teng GG, Yuan J-M, Koh W-P. Bidirectional association between diabetes and gout: the Singapore Chinese health study. Sci Rep. 2016;6: 25766.

30. Merola JF, Wu S, Han J, Choi HK, Qureshi AA. Psoriasis, psoriatic arthritis and risk of gout in US men and women. Ann Rheum Dis. 2015;74(8):1495-500.

31. Wang W, Bhole VM, Krishnan E. Chronic kidney disease as a risk factor for incident gout among men and women: retrospective cohort study using data from the Framingham heart study. BMJ Open. 2015;5(4):e006843. https://doi.org/10.1136/bmjopen-2014-006843.

32. Tan VS, Garg AX, McArthur E, Lam NN, Sood MM, Naylor KL. The 3-Year Incidence of Gout in Elderly Patients with CKD. Clin J Am Soc Nephrol. 2017;12(4):577-584. Epub 2017/02/06. https://doi.org/10.2215/CJN.06790616. PubMed PMID: 28153936; PubMed Central PMCID: PMCPMC5383383.

33. McAdams DeMarco MA, Maynard JW, Baer AN, Gelber AC, Young JH, Alonso $A$, et al. Diuretic use, increased serum urate levels, and risk of incident gout in a population-based study of adults with hypertension: the atherosclerosis risk in communities cohort study. Arthritis Rheumatism. 2012;64(1):121-9. https://doi.org/10.1002/art.33315.

34. Wijnands JMA, van Durme CMPG, Driessen JHM, Boonen A, Klop C, Leufkens $B$, et al. Individuals with type 2 diabetes mellitus are at an increased risk of gout but this is not due to diabetes: a population-based cohort study. Medicine (Baltimore) 2015;94(32):e1358-e. https://doi.org/10.1097/MD. 0000000000001358. PubMed PMID: 26266391.

35. Niu S-W, Chang K-T, Lin HY-H, Kuo I-C, Chang Y-H, Chen Y-H, et al. Decreased incidence of gout in diabetic patients using pioglitazone. Rheumatology. 2017;57(1):92-9. 
36. Roubenoff R, Klag MJ, Mead LA, Liang K, Seidler AJ, Hochberg MC. Incidence and risk factors for gout in white men. JAMA. 1991;266(21):3004-7. https://doi. org/10.1001/jama.1991.03470210072035.

37. Must A, Jacques PF, Dallal GE, Bajema CJ, Dietz WH. Long-term morbidity and mortality of overweight adolescents. N Engl J Med 1992;327(19): 1350-1355. https://doi.org/10.1056/NEJM199211053271904. PubMed PMID: 1406836.

38. Maynard JW, McAdams DeMarco MA, Baer AN, Köttgen A, Folsom AR, Coresh J, et al. Incident gout in women and association with obesity in the atherosclerosis risk in communities (ARIC) study. Am J Med. 2012;125(7):717. e9-e17. https://doi.org/10.1016/j.amjmed.2011.11.018.

39. McAdams DeMarco MA, Maynard JW, Huizinga MM, Baer AN, Köttgen A, Gelber AC, et al. Obesity and younger age at gout onset in a communitybased cohort. Arthritis Care Res. 2011;63(8):1108-14. https://doi.org/10.1002/ acr.20479.

40. Wallace SL, Robinson H, Masi AT, Decker JL, McCarty DJ. Yü Ts-f. preliminary criteria for the classification of the acute arthritis of primary gout. Arthritis \& Rheumatism. 1977;20(3):895-900. https://doi.org/10.1002/art.1780200320.

\section{Publisher's Note}

Springer Nature remains neutral with regard to jurisdictional claims in published maps and institutional affiliations.

Ready to submit your research? Choose BMC and benefit from:

- fast, convenient online submission

- thorough peer review by experienced researchers in your field

- rapid publication on acceptance

- support for research data, including large and complex data types

- gold Open Access which fosters wider collaboration and increased citations

- maximum visibility for your research: over $100 \mathrm{M}$ website views per year

At BMC, research is always in progress.

Learn more biomedcentral.com/submissions 